\title{
Characteristics of TGPGC on Short Micro Packed Capillary Column
}

\author{
Hong ZHAO,*,** Lihua YU,* Jian Zhang,* and Yafeng GUAN** \\ *The Department of Environmental Science and Engineering, Dalian Railway Institute, \\ Liaoning, 116028, P. R. China \\ **Dalian Chemical Physics Research Institute, The Academy of China, 116023, P. R. China
}

(Received September 30, 2001; Accepted November 19, 2001)

\section{Introduction}

Gas chromatography has been widely used all over the world. It is said that more than 300000 GC instruments are in use today, ${ }^{1,2}$ but only two modes of operation are widely used ${ }^{3,4}$. isothermal gas chromatography (ITGC) and programmed temperature gas chromatography (PTGC). A different operational mode for conducting GC analysis has been put forward recently, ${ }^{5-9}$ which is thermal gradient programmed gas chromatography (TGPGC). ITGC has long been applied to analyze complex samples with a narrow range of boiling temperatures. Under certain conditions, the analysis time is short and the resolution is very high without any limits of oven temperature. PTGC mode successfully separates samples with a wide range of molecular weights. With a long column and a small temperature-programming rate, a high resolution can be achieved but the analysis cannot be conducted rapidly. In fact, only a short part of the column provides an effective chromatography process when the temperature-programming rate is comparatively high. ${ }^{89}$ TGPGC is still in its early stage of development. Its main objective is to provide rapid separation with any range of molecular weight. ${ }^{8}$ Rubey $^{8,9}$ and Yuan ${ }^{10,11}$ have done a lot of pioneering probes in the field. Rubey has invented a new instrument assembly to perform the operation on open tubular column successfully. ${ }^{12}$ When we tried to devise a mini-size gas chromatograph for the detection of natural gas, we were attracted by its great potential utilities in rapid analysis and good sensitivity. Because of the requirements of the portable instrument and the main goals of our detection, we used a short micro packed capillary column instead of an open-tubular column. This change also helped us to understand the theory and characteristics of TGPGC easily.

\section{Theory}

It is quite clear that only one dimension is required to present ITGC and two dimensions to illustrate PTGC, while three dimensions are needed to describe the thermal field that is fit for TGPGC. This is the fundamental characteristic of TGPGC. The second concept about TGPGC is that a solute zone continually encounters a negative thermal gradient throughout its chromatographic axial migration. Therefore axial velocity is decreased continuously, which is the third characteristic of TGPGC. In one word there is an axial compressing effect, which in return gives a negative contribution in standard deviation. When the diffusion effect is fixed, the distance variance of TGPGC is the smallest among the three modes. ${ }^{8,13,15}$ On account of the resolution of TGPGC, we must take into consideration many factors: its compression effect, temperature programming rate, etc. The assumption has been put forward that the resolution of TGPGC could be as big as that of PTGC if the axial thermal gradient is small enough. ${ }^{16-19}$ As we all know, the bigger the retention factor is, the bigger the temperature variation is. Therefore the effect of thermal gradient is greater in low temperature range than in high range. In order to make clear the correlation between the axial gradient and the resolution, and furthermore to make an overall evaluation of TGPGC mode, we applied TGPGC on a short packed capillary column, to separate complex samples with low molecular weights, such as $\mathrm{C} 1-\mathrm{C} 7$ hydrocarbons. A short packed column has the advantages of big column retention factor and small plate height. Moreover, a big thermal gradient can be achieved easily and the thermal equilibrium can be avoided as well.

\section{Instruments and Chemicals}

The role of the TGPGC instrumentation in our experiment is to facilitate the exploring experiments, especially to systematically understand and fully characterize this mode on a short packed column. Another consideration of the instrument is to minimize the $\mathrm{GC}$ analyzer. We made use of a round brass plate with diameter $200 \mathrm{~mm}$ and thickness $0.5 \mathrm{~mm}$. A column with different thickness asbestos sheaths was arranged along the Archimedes spiral line. A small heating plate with an adjuster was attached in the center of the brass plate in order to supply and keep a constant thermal gradient. The inlet of the column was at the center of the brass (Fig. 1). First we tested the relationship between the voltage and the thermal gradient by four pairs of $\mathrm{Ni}-\mathrm{Cr}$ thermal electrical couples fixed along the column. The axial thermal gradient was proportional to the square of the voltage applied. Then we assembled the whole set into a gas chromatograph (1102, Shanghai Analyzer Factory, China). The short micro packed column is made of quartz, 70 $\mathrm{cm} \times 0.53 \mathrm{~mm}$ i.d., and with PROPACK-Q (Waters Associate Inc. USA; specific area $600-800 \mathrm{~m}^{2} / \mathrm{g}$; density, $0.25-0.35$ $\mathrm{g} / \mathrm{ml}$; diameter $75-400 \AA$ ) as stationary phase. The temperature of detector and injector was $220^{\circ} \mathrm{C}$ and $150^{\circ} \mathrm{C}$ respectively. The plate number was about 850 at room temperature when the flow rate of carrier gas was $4 \mathrm{ml} / \mathrm{min}$. 


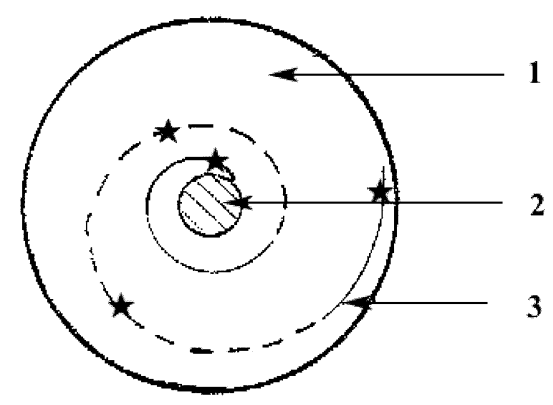

Fig. 1 The schematic figure of the setting. $\star$, thermocouple; 1 , brass plate; 2 , heating plate; 3 , capillary column with asbestos sheath.

\section{Results and Discussion}

\section{The comparison between TGPGC and ITGC}

In this experiment, the oven temperature was $30^{\circ} \mathrm{C}$ and the thermal gradient was about $1^{\circ} \mathrm{C} / \mathrm{cm}$. During the experiments no temperature-programming was applied. The temperature of the inlet was about $100^{\circ} \mathrm{C}$ and that of the outlet was $30^{\circ} \mathrm{C}$ in TGPGC mode. The results are shown in Figs. 2 and 5. We can see from the result that the notable advantages of TGPGC are its quickness and sharpness in analysis. Under the condition that the loss of the resolution is not too big, that is, if the resolution can meet the requirements, the increase in sensitivity and analysis speed is more desirable.

\section{The comparison between TGPGC and PTGC}

Here, the oven temperature was $30^{\circ} \mathrm{C}$ and the temperatureprogramming rates were $5^{\circ} \mathrm{C} / \mathrm{min}$ and $10^{\circ} \mathrm{C} / \mathrm{min}$, respectively. The other operational conditions remained the same as above. The results are shown in Figs. 3 and 4. The sharpness of the half wave width of TGPGC is remarkable at this time and the difference in analysis time between the two modes is getting smaller and smaller as the temperature-programming rate increased. Here, we could see in both cases, although the differences of analysis time and half wave width were noticeable, that the difference between the resolutions was comparable. The reason may be that we applied a quite small flow rate $(4 \mathrm{ml} / \mathrm{min})$ and made use of the characteristic separation (butanol and propanol, $\gamma=1.23,1.17$ in two cases, $\gamma$ : relative retention value) of PROPACK-Q as the two analytes to specify the resolution. The variation of the temperature as well as programming-temperature rate have a big effect on the analysis time and half wave width when the effect of flow rate is neglectable. In fact, the resolution in both cases was not perfect because the temperature we applied in the experiments was a little too high to separate the analytes. ${ }^{14}$

The relationship between axial thermal gradient and the resolution

We kept the same temperature-programming rate, about $5^{\circ} \mathrm{C} / \mathrm{min}$, and changed the axial thermal gradient as follows: $1^{\circ} \mathrm{C} / \mathrm{cm}, 1.5^{\circ} \mathrm{C} / \mathrm{cm}, 2^{\circ} \mathrm{C} / \mathrm{cm}$. The resolution loss was noticeable. A thermal reversal occurred, which means bigger loss of the resolution for peaks (when thermal gradient was equal to $2^{\circ} \mathrm{C} / \mathrm{cm}$ ). But since the total temperature difference between the inlet and the outlet is about as high as $100^{\circ} \mathrm{C} / \mathrm{m}$ (the axial thermal gradient is only $1^{\circ} \mathrm{C} / \mathrm{cm}$ ), the good aspects of axial thermal gradient are quite effective. To increase the temperature by $100^{\circ} \mathrm{C}$ and keep the temperature-programming

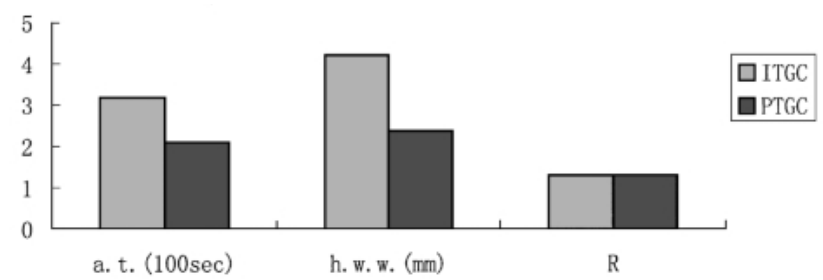

Fig. 2 The comparison of ITGC and TGPGC. a. t., analysis time (butanol); h. w. w., half wave width (butanol); R, resolution (propanol and butanol, $\gamma=1.44$ ); flow rate, $4 \mathrm{ml} / \mathrm{min}$; temp., $30^{\circ} \mathrm{C}$; axial thermal gradient, $1^{\circ} \mathrm{C} / \mathrm{cm}$.

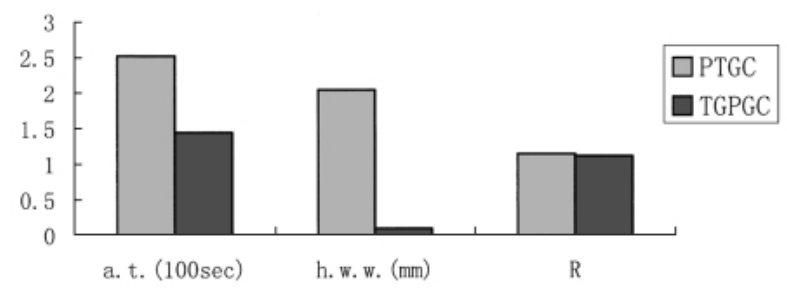

Fig. 3 The comparison of PTGC and TGPGC. Starting temperature, $30^{\circ} \mathrm{C}$; temperature-programming rate, $5^{\circ} \mathrm{C} / \mathrm{min}$; axial thermal gradient, $1^{\circ} \mathrm{C} / \mathrm{min}$; $\mathrm{R}$, resolution (propanol and butanol, $\gamma=$ $1.23)$.

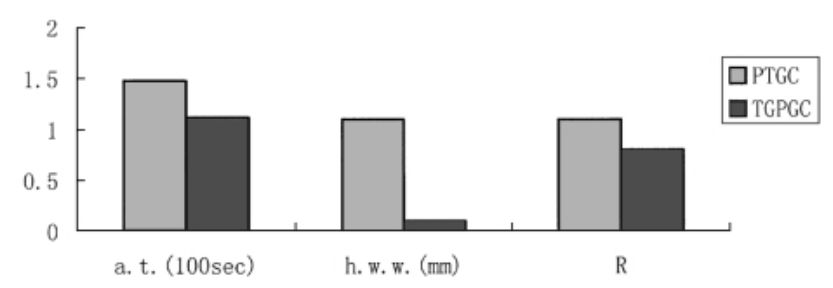

Fig. 4 The comparison of PTGC and TGPGC. Starting temperature, $30^{\circ} \mathrm{C}$; temperature-programming rate, $10^{\circ} \mathrm{C} / \mathrm{min}$; axial thermal gradient, $1^{\circ} \mathrm{C} / \mathrm{min}$; $\mathrm{R}$, resolution (propanol and butanol, $\gamma=1.17$ ).

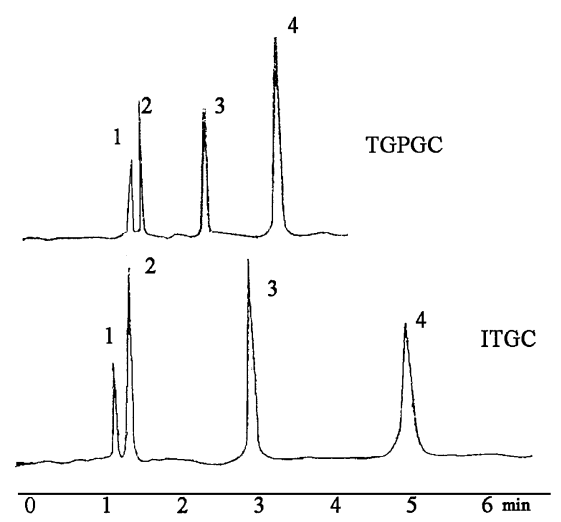

Fig. 5 The chromatograph of TGPGC and ITGC. 1, methanol; 2, ethanol; 3, propanol; 4, butanol. All the chromatographic conditions are the same as in Fig. 2.

rate $1^{\circ} \mathrm{C} / \mathrm{min}$, we need $100 \mathrm{~min}$ to realize the operation. This is why we need to make deeper research into TGPGC. ${ }^{16,17}$ 


\section{Conclusions}

We did this exploring experiment of TGPGC on a short micro packed capillary column initially in order to devise a portable gas chromatograph for detecting natural gas quickly and easily. The requirements of a set of small instruments and quick analysis asked us to try different operational modes. We were glad to find the TGPGC mode does have several remarkable advantages: quickness and sharpness, which are just what we need. We must admit that TGPGC is still in its early developing stage and there are so many uncertain factors to be fixed. The instrument to realize the best results is still a big challenge also.

\section{References}

1. G. Gasper, R. Annino, and C. Vidal-Madja, Anal. Chem., 1978, 50, 1512.

2. C. A. Aramera, F. A. Wijnheymer, and J. A. Rijks, $H R C$ \& CC, 1979, 2, 329.

3. A. K. Bemgard, L. G. Blomberg, and A. L. Colmsjo, Anal. Chem., 1989, 61, 2165.

4. W. E. Harris and H. W. Habgood, "Programmed Temperature Gas Chromatography", 1968, Wiley, New York.
5. A. Zhukhovitskii, O. Zolotareva, V. A. Sokolov, and N. M. Turkel'taubl, Dokl. Akad. Nauk. SSSR., 1951, 77, 435.

6. M. Coudert, J. Larrat, and J. N. Verhnaud, J. Chromatogr., 1971, 58, 159.

7. W. A. Rubey, 32nd Annual Rock Mountain Conference on Analytical Chemistry, 1990, Denver.

8. W. A. Rubey, $H R C, \mathbf{1 9 9 1}, 14,542$.

9. W. A. Rubey, $H R C, \mathbf{1 9 9 2}, 15,795$.

10. X. Yuan, Hunan Daxue Xuebao, 1997, 23(4), 51.

11. X. Yuan, Hunan Daxue Xuebao, 1999, 26(3), 21.

12. W. A. Rubey, Rev. Sci. Instrum., 1994, 65, 2802.

13. U. G. Berdzkin, T. Y. Chernysheva, V. V. Buzayeu, and M. A. Koshevnik, J. Chromatogr., 1986, 373, 21.

14. Analytical Chem. Teaching and Research Group, Chengdu University of Sci. \& Tech., "Handbook of Analytical Chemistry", 1984, Chem. Industrial Press, Beijing, China, 53, 57, $197-199$.

15. R. W. Ohline, Ph. D. Thesis, Northwestern University, 1960.

16. W. A. Rubey, Paper Presented at the International Symposiom on Capillary Chromatography in Riva Del, 1989, Italy.

17. W. A. Rubey, U. S. Air Force Wright Laboratories Technical Report, WL-TR-92-2053, 1992.

18. L. M. Blumberg, Anal. Chem., 1992, 64, 2459.

19. L. M. Blumberg and T. A. Bengerg, J. Chromatogr., 1992, 596, 1 . 